\title{
Replacing Sugar Sweetened Beverages with Plain Water Improves Body Composition among Female Youth
}

\author{
Nur Islami Mohd Fahmi Teng ${ }^{1, *}$, Sa'ida Munira Johari', Nur Azma Amin ${ }^{3}$, \\ Hazwan Shah $\mathrm{Ali}^{1}$, Siti Hajar Mukhtar ${ }^{1}$, Norsham Juliana Nordin ${ }^{2}$ \\ ${ }^{1}$ Faculty of Health Sciences, Universiti Teknologi MARA, Selangor, Malaysia \\ ${ }^{2}$ Faculty of Medicine and Health Sciences, Universiti Sains Islam Malaysia, Kuala Lumpur, Malaysia \\ ${ }^{3}$ Institute of Medical Science Technology, Universiti Kuala Lumpur, Selangor, Malaysia \\ *Corresponding author: nurislami@puncakalam.uitm.edu.my
}

\begin{abstract}
Sugar-sweetened beverage (SSB) intake is considered an important contributing factor to obesity in youth. Replacing SSB with calorie-free beverage has potentially reduced energy intake and obesity prevention; however the health outcomes remain unclear. We evaluated the effect of the substitution of plain water for SSBs with incident of obesity in female youth. We conducted a two months intervention on plain water intake. A total of 43 overweight female (age $22.0 \pm 2.6$ years) were randomly assigned to Intervention $(n=23)$ and Control $(n=20)$ groups. The intervention regime consists of increasing intake of daily plain water consumption, and avoiding SSB. However, intake of 1 serving of fresh milk per day is allowed. Body composition measurements, diet history questionnaires (DHQ), SF-36 and goal-adjustment scale (GAS) questionnaires were ascertained at baseline and week 8. There was a significant increase $(\mathrm{p}<0.001)$ in plain water intake in the Intervention group as compared to the Control group. With respect to body composition, there was a significant intervention effect in body weight $(\mathrm{p}<0.05)$ and BMI $(\mathrm{p}<0.01)$. It was shown that both body weight and BMI improved in the Intervention group as compared to Control. Both waist circumference and body fat percentage revealed significant group effect $(\mathrm{p}<0.05)$. No significant intervention effect was found on both SF-36 and GAS items. Replacing SSB with plain water is effective in improving body composition among youth. There is a need to conduct a larger scale study with longer duration and measuring biochemical parameters for further research.
\end{abstract}

Keywords: obesity, overweight, plain water, sugar sweetened beverages

Cite This Article: Nur Islami Mohd Fahmi Teng, Sa’ida Munira Johari, Nur Azma Amin, Hazwan Shah Ali, Siti Hajar Mukhtar, and Norsham Juliana Nordin, "Replacing Sugar Sweetened Beverages with Plain Water Improves Body Composition among Female Youth.” Journal of Food and Nutrition Research, vol. 5, no. 9 (2017): 684-688. doi: 10.12691/jfnr-5-9-8.

\section{Introduction}

The increase in obesity prevalence is one of the world's public health concerns. Among Malaysian adult population, the prevalence of obesity was $17.7 \%$ (defined using WHO 2000 criteria) which was higher than the world's prevalence, $13.0 \%$ [1]. This prevalence had increased $0.6 \%$ than the previous report in 2011 [2]. In detail, the prevalence of obesity among female adults (20.6\%) was significantly higher than male (15.0\%). Moreover the prevalence of diabetes mellitus (DM), although not significant, was also higher among female (18.3\%) as compared to male (16.7\%) [1].

Drinking sugar-sweetened beverages (SSB) appears to be the most important contributor to the obesity epidemic. It was found to be the largest source of added sugar thus, being the major contributor of energy in the diet of youth $[3,4]$. Other than obesity [5], consumption of SSB has been associated with type 2 diabetes [6], dental caries [7], poor mental health [8], poor academic grades [9] and displacement of nutrient-rich foods [10].

Conversely, drinking plain water (PW) is a healthful alternative for SSB. Intake of PW is one approach for reducing total energy intake [11]. Scientific evidence has reported that PW intake was inversely associated with intake of total sugar, suggestive of poor diet quality [12]. Therefore, there is a possible benefit of obesity prevention and control by drinking plain water. As part of a healthy diet, drinking plain water can aid weight management $[13,14]$ and if replaced for SSB intake, there will be a possibility to avert the adverse consequences associated with SSB.

Hence, there is a need for conclusive evidence whether the approach of replacing SSB with plain water can improve body weight and composition among this group of population. To date, generally very few studies in Asia region have reported the consumption of beverage in particular related to the intake of SSB and plain water. The aim of this current study was to contribute to the limited evidence base by investigating the effectiveness of replacing SSB with plain water. We hypothesized that higher plain water intake will improve body composition, and quality of life parameters. 


\section{Method}

\subsection{Study Design, Subjects and Sampling}

This is a study to determine the effectiveness of replacing SSB with plain water, of two months duration among 43 overweight or obese female youth. Study participants were recruited from a local university in central Malaysia. Participants were screened based on body mass index (BMI) using World Health Organization (15) criteria. Inclusion criteria were overweight female aged 18 - 25 years, and have no other chronic diseases. Exclusion criteria include pregnancy and lactation, smokers, and those who had change their usual dietary pattern over the previous 3 months.

\subsection{The Intervention}

Subjects were randomly assigned to Control and Intervention group. Control group needs to maintain their present nutritional habits and lifestyle, while intervention group needs to adhere to the intervention plan. The intervention regimen consists of increasing intake of daily plain water consumption, and avoiding sugar sweetened beverages. However, intake of 1 serving of fresh milk per day is allowed. Subjects were also instructed to not changing their activity level throughout the intervention period.

Compliance to the intervention was assessed using daily water consumption log book, and verification of the information obtained during baseline, week 4 and week 8 .

\subsection{Data Collection}

Data was collected twice, at baseline and 2 months after the intervention. The instruments used for measuring anthropometry include Seca 271 Portable Stadiometer for height measurement, Seca Robusta 813 Weighing Scale for weight measurement, Omron HBF-3060C Body Fat Analyzer for body fat percentage measurement and Seca 201 Measuring Tape for waist circumference measurement. Dietary information was gathered using 24-hour diet recall interview, and further analysed using Nutritionist Pro software. Further, a set of web based questionnaire was administered to the participants. The self-administered questionnaire includes Short-form 36 health status questionnaire (SF-36) and Goal Adjustment Scale Questionnaire (GAS). All of these questionnaires have underwent reliability and validity testing by previous studies.
Ethical approval for this study was obtained from Universiti Teknologi MARA Research Ethics Committee and informed consent was obtained from all subjects.

\subsection{Statistical Analysis}

Analyses were carried out using SPSS version 21.0. Changes from baseline to week 8 were analysed using repeated measures ANOVA with baseline values included as covariates. Result are presented with three $\mathrm{p}$ values and partial eta square: i) time effect, to test whether there was a change over time; ii) group effect, to test the difference between both groups throughout the intervention period; iii) intervention effect, which is the test of main or interaction effect.

\section{Results}

\subsection{Baseline Characteristics}

A total of 43 female youth subjects (Control group, $\mathrm{n}=20$; Intervention group, $\mathrm{n}=23$ ) completed this study. For sociodemographic profile, all of the participants were single (not married) and still studying in the university. Baseline characteristics of the two study groups are shown in Table 1. No significant differences between groups were found for all of the parameters, except for body fat percentage $(p<0.05)$. At baseline, fat percentage in Intervention group was significantly higher than Control, thus it was included as the covariate in the analysis of repeated measured ANOVA.

\subsection{Repeated Measures Effect}

Table 2 presents the plain water intake, energy and anthropometry data of the subjects at baseline and week 8 . There was a significant increase $(\mathrm{p}<0.001)$ in plain water intake in the Intervention group as compared to the Control group. Plain water intake was increased by $+53.4 \%$ in the Intervention group compared to a $+1.0 \%$ increase in the Control group.

With respect to body composition, there was a significant intervention effect in body weight $(\mathrm{p}<0.05)$ and BMI $(\mathrm{p}<0.01)$. It was shown that both body weight and BMI improved in the Intervention group as compared to Control group following the intervention. Both waist circumference and body fat percentage revealed significant group effect $(\mathrm{p}<0.05)$.

Table 1. Baseline characteristics of participants

\begin{tabular}{|c|c|c|c|}
\hline Characteristics & Intervention group $(n=23)$ & Control group $(n=20)$ & $\mathrm{P}$ value \\
\hline Age & $21.8 \pm 2.8$ & $22.4 \pm 2.6$ & 0.721 \\
\hline Weight (kg) & $73.6 \pm 16.3$ & $67.0 \pm 10.6$ & 0.099 \\
\hline BMI $\left(\mathrm{kg} / \mathrm{m}^{2}\right)$ & $29.7 \pm 4.8$ & $27.4 \pm 2.6$ & 0.374 \\
\hline Waist circumference (cm) & $89.2 \pm 16.4$ & $91.9 \pm 18.3$ & 0.621 \\
\hline Body fat (\%) & $38.4 \pm 4.5$ & $31.3 \pm 6.6$ & $0.01^{*}$ \\
\hline Energy intake (kcal/day) & $1753 \pm 736$ & $2163 \pm 711$ & 0.072 \\
\hline Plain water intake (ml/day) & $513 \pm 385$ & $737 \pm 552$ & 0.126 \\
\hline
\end{tabular}


Table 2. Changes in body composition, energy and water intake

\begin{tabular}{|c|c|c|c|c|c|}
\hline \multirow{2}{*}{ Variable } & \multirow{2}{*}{ Baseline (mean \pm SD) } & \multirow{2}{*}{ Week 8 (mean \pm SD) } & \multicolumn{3}{|c|}{ p (partial eta square) } \\
\hline & & & Time effect & Group effect & Intervention effect \\
\hline \multicolumn{6}{|c|}{ Plain water intake (ml/day) } \\
\hline Intervention $(\mathrm{n}=23)$ & $513 \pm 385$ & $1102 \pm 558$ & $0.457(0.014)$ & $0.998(0.000)$ & $0.000(0.336)^{* * *}$ \\
\hline Control $(n=20)$ & $737 \pm 552$ & $745 \pm 560$ & & & \\
\hline \multicolumn{6}{|l|}{ Energy intake (kcal/day) } \\
\hline Intervention $(\mathrm{n}=23)$ & $1753 \pm 736$ & $1552 \pm 485$ & $0.736(0.003)$ & $0.082(0.074)$ & $0.318(0.025)$ \\
\hline Control $(n=20)$ & $2163 \pm 711$ & $2245 \pm 467$ & & & \\
\hline \multicolumn{6}{|l|}{ Weight $(\mathrm{kg})$} \\
\hline Intervention $(n=23)$ & $73.6 \pm 16.3$ & $71.4 \pm 16.7$ & $0.006(0.222)^{* *}$ & $0.466(0.013)$ & $0.018(0.132)^{*}$ \\
\hline Control $(n=20)$ & $67.0 \pm 10.6$ & $68.5 \pm 8.1$ & & & \\
\hline \multicolumn{6}{|l|}{$B M I\left(\mathrm{~kg} / \mathrm{m}^{2}\right)$} \\
\hline Intervention $(\mathrm{n}=23)$ & $29.7 \pm 4.8$ & $28.7 \pm 4.9$ & $0.041(0.121)^{*}$ & $0.05(0.096)$ & $0.002(0.130)^{* *}$ \\
\hline Control $(n=20)$ & $27.4 \pm 2.6$ & $28.8 \pm 2.9$ & & & \\
\hline \multicolumn{6}{|l|}{ Waist circumference $(\mathrm{cm})$} \\
\hline Intervention $(\mathrm{n}=23)$ & $89.2 \pm 16.4$ & $87.5 \pm 15.5$ & $0.762(0.093)$ & $0.036(0.106)^{*}$ & $0.102(0.065)$ \\
\hline Control $(n=20)$ & $91.9 \pm 18.3$ & $92.9 \pm 16.9$ & & & \\
\hline \multicolumn{6}{|l|}{ Body fat (\%) } \\
\hline Intervention $(\mathrm{n}=23)$ & $38.4 \pm 4.5$ & $35.1 \pm 9.6$ & $0.111(0.061)$ & $0.006(0.169)^{* *}$ & $0.112(0.061)$ \\
\hline Control $(n=20)$ & $31.3 \pm 6.6$ & $31.3 \pm 5.0$ & & & \\
\hline
\end{tabular}

* significant at $\mathrm{p}<0.05$, analysis using Repeated Measures ANOVA

** significant at $\mathrm{p}<0.01$, analysis using Repeated Measures ANOVA

*** significant at $\mathrm{p}<0.001$, analysis using Repeated Measures ANOVA.

Table 3. Changes in Quality of Life

\begin{tabular}{|c|c|c|c|c|c|}
\hline \multirow{2}{*}{ Variable } & \multirow{2}{*}{ Baseline (mean \pm SD) } & \multirow{2}{*}{ Week 8 (mean \pm SD) } & \multicolumn{3}{|c|}{$\mathrm{p}$ (partial eta square) } \\
\hline & & & Time effect & Group effect & Intervention effect \\
\hline \multicolumn{6}{|l|}{ SF-36 Physical function } \\
\hline Intervention $(\mathrm{n}=23)$ & $56.7 \pm 16.6$ & $64.6 \pm 17.8$ & $0.175(0.044)$ & $0.033(0.107)^{*}$ & $0.540(0.009)$ \\
\hline Control $(n=20)$ & $73 \pm 28.9$ & $76.0 \pm 31.6$ & & & \\
\hline \multicolumn{6}{|c|}{ Functional limitation (physical) } \\
\hline Intervention $(\mathrm{n}=23)$ & $75.9 \pm 21.1$ & $66.3 \pm 25.1$ & $0.65(0.005)$ & $0.773(0.003)$ & $0.252(0.032)$ \\
\hline Control $(n=20)$ & $66.3 \pm 42.7$ & $70.4 \pm 38.7$ & & & \\
\hline \multicolumn{6}{|c|}{ Functional limitation (emotion) } \\
\hline Intervention $(\mathrm{n}=23)$ & $23.5 \pm 16.9$ & $28.7 \pm 15.2$ & $0.199(0.040)$ & $0.000(0.439)^{* * *}$ & $0.683(0.004)$ \\
\hline Control $(n=20)$ & $61.7 \pm 43.6$ & $71.7 \pm 37.8$ & & & \\
\hline \multicolumn{6}{|l|}{ Vitality } \\
\hline Intervention ( $\mathrm{n}=23$ ) & $55.4 \pm 10.9$ & $54.6 \pm 6.4$ & $0.612(0.006)$ & $0.869(0.001)$ & $0.864(0.001)$ \\
\hline Control $(n=20)$ & $55.5 \pm 15.7$ & $53.8 \pm 10.2$ & & & \\
\hline \multicolumn{6}{|l|}{ Emotional well being } \\
\hline Intervention $(\mathrm{n}=23)$ & $61.6 \pm 15.2$ & $61.6 \pm 14.2$ & $0.553(0.009)$ & $0.133(0.054)$ & $0.579(0.008)$ \\
\hline Control $(n=20)$ & $55.8 \pm 8.8$ & $58.4 \pm 7.4$ & & & \\
\hline \multicolumn{6}{|l|}{ Social function } \\
\hline Intervention $(\mathrm{n}=23)$ & $61.4 \pm 16.8$ & $59.8 \pm 16.4$ & $0.234(0.034)$ & $0.207(0.039)$ & $0.077(0.074)$ \\
\hline Control $(n=20)$ & $61.3 \pm 14.0$ & $69.4 \pm 11.0$ & & & \\
\hline \multicolumn{6}{|l|}{ Pain } \\
\hline Intervention $(\mathrm{n}=23)$ & $61.9 \pm 15.8$ & $67.0 \pm 19.6$ & $0.200(0.040)$ & $0.672(0.04)$ & $0.886(0.001)$ \\
\hline Control $(n=20)$ & $60.4 \pm 20.5$ & $64.4 \pm 22.3$ & & & \\
\hline \multicolumn{6}{|l|}{ General health } \\
\hline Intervention $(\mathrm{n}=23)$ & $58.5 \pm 15.0$ & $61.6 \pm 15.0$ & $0.639(0.005)$ & $0.786(0.002)$ & $0.106(0.063)$ \\
\hline Control (n=20) & $61.9 \pm 18.3$ & $56.3 \pm 9.6$ & & & \\
\hline \multicolumn{6}{|l|}{ GAS Goal disengagement } \\
\hline Intervention (n=23) & $11.7 \pm 2.3$ & $10.8 \pm 1.4$ & $0.501(0.011)$ & $0.026(0.115)^{*}$ & $0.007(0.167)$ \\
\hline Control $(n=20)$ & $11.5 \pm 2.2$ & $13.0 \pm 1.9$ & & & \\
\hline \multicolumn{6}{|l|}{ Goal reengagement } \\
\hline Intervention $(\mathrm{n}=23)$ & $19.9 \pm 5.6$ & $19.4 \pm 4.1$ & $0.931(0.000)$ & $0.028(0.113)^{*}$ & $0.568(0.008)$ \\
\hline Control $(n=20)$ & $21.4 \pm 4.9$ & $22.1 \pm 1.8$ & & & \\
\hline
\end{tabular}




\subsection{Quality of Life}

As shown in Table 3, physical function and functional limitation (emotion) was significantly different $(\mathrm{p}<0.05)$ in both Intervention and Control group. Although both groups showed increased in physical function over time, there was greater increase in Intervention vs Control. As for Goal Adjustment analysis, there was a significant group effect $(\mathrm{p}<0.05)$, but no significant difference over time.

\section{Discussion}

Calorie vs non-calorie beverage intake plays a big role in determining daily calorie intake. Higher intake of sweetened beverages may contribute to high energy intake which subsequently affect one's body weight and also associate with chronic diseases. Our study indicates that by increasing consumption of plain water and cutting all sugar-sweetened beverages for 2 months is beneficial in reducing body weight and BMI significantly. Although no significant difference observed, energy intake, waist circumference and body fat percentage were also reduced following this intervention.

Plain water intake together with proper diet may enhance weight loss [13]. As there is no additional calorie from sugar sweetened beverages, there will be energy intake reduction, thus help reducing body weight especially in overweight and obese. Plain water intake may also promote fullness to the stomach and did not differ in their ability to suppress hunger than the SSB [16]. It may also promotes hydration, increase satiety and thermogenesis, therefore reduce intake of other food [17].

A Study by Hruby et al. [18] found that intakes of sweetened beverage may increase weight. Further, it was also reported that visceral fat accumulation is due to the sucrose or fructose in SSB that will lead to lipogenesis and insulin resistance [19]. Carbohydrate will be converted to glycogen; however, the excess carbohydrate will be converted to fat, stored in adipose tissue, and eventually increase body fat percentage.

In this study, at baseline, we found that intake of PW in both groups were low. After 8 weeks, the PW intake increased significantly in the Intervention group, however remained low in the Control group. Low intake of PW may indicate either poor hydration status or poor nutrition if it was replaced by other SSB. In the present study, energy intake in Control group was higher than Intervention, which may reflect higher intake of caloric beverages in the Control group.

Our study showed no intervention effect as measured by SF-36 and GAS questionnaire. Of remark however general health of the Intervention group was increased and no detrimental effect observed following the intervention. With regards to GAS, the present study found no intervention effects on goal disengagement and goal reengagement capacities. The GAS measures how the participants react when they were participating in this study and to pursue the goals of the intervention. Since all the participants in our study were overweight, it is particularly important to measure their attainment towards achieving normal body weight and healthy lifestyle. The goals may become unattainable if the participants encounter stress following the intervention regime. Likely, there is no such circumstance observed in our study.

\section{Conclusion}

In conclusion, this study showed that PW intervention is effective in improving body composition among female youth. There is a need to conduct a larger scale study with longer duration and measuring biochemical parameters for further research.

\section{Acknowledgements}

We are grateful to the participants, fieldworker and others involved in the data collection. We acknowledge the financial support from the research grant of Universiti Sains Islam Malaysia (USIM/FRGS/FPSK/32/51415).

\section{References}

[1] Health IoP. National Health and Morbidity Survey (NHMS) 2015. Malaysia; 2015.

[2] Health IfP. National Health and Morbidity Survey 2011 (NHMS 2011). Malaysia; 2011.

[3] Kosova EC, Auinger P, Bremer AA. The relationships between sugar-sweetened beverage intake and cardiometabolic markers in young children. Journal of the Academy of Nutrition and Dietetics 2013; 113(2):219-227.

[4] Reedy J, Krebs-Smith SM. Dietary sources of energy, solid fats, and added sugars among children and adolescents in the United States. Journal of the American Dietetic Association 2010; 110(10):1477-1484.

[5] Fiorito LM, Marini M, Francis LA, Smiciklas-Wright H, Birch LL. Beverage intake of girls at age $5 \mathrm{y}$ predicts adiposity and weight status in childhood and adolescence. The American journal of clinical nutrition 2009; 90(4):935-942.

[6] Malik VS, Popkin BM, Bray GA, Després J-P, Willett WC, Hu FB Sugar-sweetened beverages and risk of metabolic syndrome and type 2 diabetes. Diabetes care 2010; 33(11):2477-2483.

[7] Sohn W, Burt BA, Sowers MR. Carbonated soft drinks and dental caries in the primary dentition. Journal of dental research 2006; 85(3): 262-266.

[8] Shi Z, Taylor AW, Wittert G, Goldney R, Gill TK. Soft drink consumption and mental health problems among adults in Australia. Public health nutrition 2010; 13(7):1073-1079.

[9] Park S, Sherry B, Foti K, Blanck HM. Self-reported academic grades and other correlates of sugar-sweetened soda intake among US adolescents. Journal of the Academy of Nutrition and Dietetics 2012; 112(1): 125-131.

[10] Marshall TA, Eichenberger Gilmore JM, Broffitt B, Stumbo PJ, Levy SM. Diet quality in young children is influenced by beverage consumption. Journal of the American College of Nutrition 2005; 24(1): 65-75.

[11] Park S, Blanck HM, Sherry B, Brener N, O'Toole T. Factors associated with low water intake among US high school students-National Youth Physical Activity and Nutrition Study, 2010. Journal of the Academy of Nutrition and Dietetics 2012; 112(9): 1421-1427.

[12] Kant AK, Graubard BI. Contributors of water intake in US children and adolescents: associations with dietary and meal characteristics: National Health and Nutrition Examination Survey 2005-2006. The American journal of clinical nutrition 2010:ajcn. 29708.

[13] Tate DF, Turner-McGrievy G, Lyons E, Stevens J, Erickson K, Polzien K, et al. Replacing caloric beverages with water or diet beverages for weight loss in adults: main results of the Choose Healthy Options Consciously Everyday (CHOICE) randomized clinical trial. The American journal of clinical nutrition 2012; 95(3): 555-563. 
[14] Daniels MC, Popkin BM. Impact of water intake on energy intake and weight status: a systematic review. Nutrition reviews 2010; 68(9): 505-521.

[15] Organization WH. Obesity: preventing and managing the global epidemic: World Health Organization; 2000.

[16] Holt NS, JC Brand-Miller, SHA. The effects of sugar-free vs sugar-rich beverages on feelings of fullness and subsequent food intake. International journal of food sciences and nutrition 2000; 51(1): 59-71.

[17] Illescas-Zarate D, Espinosa-Montero J, Flores M, Barquera S. Plain water consumption is associated with lower intake of caloric beverage: cross-sectional study in Mexican adults with low socioeconomic status. BMC public health 2015; 15(1):405.

[18] Hruby A, Manson JE, Qi L, Malik VS, Rimm EB, Sun Q, et al. Determinants and consequences of obesity. American journal of public health 2016; 106(9): 1656-1662.

[19] Maersk M, Belza A, Stødkilde-Jørgensen H, Ringgaard S, Chabanova E, Thomsen H, et al. Sucrose-sweetened beverages increase fat storage in the liver, muscle, and visceral fat depot: a 6mo randomized intervention study. The American journal of clinical nutrition 2012; 95(2):283-289. 